\title{
Usage of Digital Tools to Access Primary Care in Quebec: An Environmental Scan
}

\author{
Jonathan LAPOINTEE, ${ }^{\mathrm{a}, \mathrm{b}, 1}$, Janine BADR ${ }^{\mathrm{a}, \mathrm{b}}$ and Aude MOTULSKY ${ }^{\mathrm{a}, \mathrm{b}}$

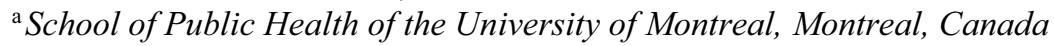 \\ ${ }^{\mathrm{b}}$ Centre de recherche du Centre Hospitalier Universitaire de l'Université de Montréal
}

\begin{abstract}
Timely access to care is a persistent challenge for health care systems. Providing the right care to the right patient at the right time is important to reduce inappropriate use and improve the performance of healthcare services. The complexity of accessing primary care contributes to the high usage of emergency rooms for not-urgent conditions. Many digital tools try to offer a better access to care for patients and reduce ER overuse. This environmental scan of the digital tools available in Quebec identifies those digital tools and some of their limitations. The results reveal the complexity of mobilizing digital tools in the healthcare sector and highlight the need for all stakeholders to work together to enhance access to care.
\end{abstract}

Keywords. mHealth, Access to care, Primary care, Adoption

\section{Introduction}

Access to primary care is challenging and has an impact on the performance of health care systems [1]. Many factors such as complex booking procedures and long wait times have a negative impact on the accessibility to appropriate care, at the right time and at the right place $[2,3]$. This contributes to the overuse of emergency rooms (ER), in turn increasing healthcare costs and having a negative impact on the patient's health and satisfaction with healthcare services [2]. In the province of Quebec, Canada, around 20\% of the population don't have a family doctor [3]. To secure a consultation with a primary care provider they must call a clinic at a specific hour to get one of the few appointments available. If they can't reach the clinic on time, they either wait another day, call another clinic, or revert to using the ER. This tiresome process is partly responsible for ER congestion, where an average of $60 \%$ of the patients are evaluated as needing low priority non-urgent care that could have been treated in primary care [4]. This contributes to an ER occupation rate of over $100 \%$, and a mean wait time of eight (8) hours for physical consultation, going up to 12 hours for mental health consultations [5].

Recently public and private actors try to address this challenge by leveraging the digital tools (mobile apps, web sites, or online platforms) to provide timely and appropriate access to care for patients. This research identifies the types and characteristics of the digital tools used to address this problem and analyze their strengths and limits. To reach these goals, it does an environmental scan of digital tools and explores the perceptions and experiences of healthcare professionals through interviews.

\footnotetext{
${ }^{1}$ Corresponding author, Jonathan Lapointe, École de Santé Publique de l’Université de Montréal, 7101 av. du Parc, Montreal, Quebec, Canada, H3N 1X9; E-mail: jonathan.lapointe.1@umontreal.ca.
} 


\section{Methodology}

The environmental scan suits our research objective by providing a rapid way of acquiring and using information to design "tailor made" interventions for a specific need [6]. For this research, data collection was conducted in 2018 using two strategies: 1) Identifying the digital tools through web search and iterative discussion with researchers and healthcare professionals to find tools used in the field. The tools had to help a patient access to care or give him information on what type of care he would need. The documentation about each tool was analyzed. Each tool was then tested using ear pain as a clinical test case as it is one of the five most common cause of non-urgent ER visit [7]. Then the tools were categorized according to their main use following agreement between the research team. 2) Four semi-structured interviews were conducted. Respondents had experience as primary care clinic manager, primary care clinic doctor and owner, ER service manager and as a physician. Interviews covered their knowledge and usage of digital tools to address patient's access to care, their implementation, and their limitations. Interviews were recorded, transcribed then coded inductively using the emerging themes related to the usage and limits of using digital tools. This gave us information on their experience using the tools and their usage in a healthcare setting.

\section{Results}

Table 1 presents the tools and the categories based on the main value proposition they offer. 1) Symptom checkers that asks the patient questions according to their symptom(s), age, sex, weight, and health history. Based on algorithms fed by machine-learning and artificial intelligence, patients are then informed by the tool on the possible symptoms' causes and probability scores. The checker can also suggest what to do next: going to the ER, seeing a health professional or observe the evolution of symptoms. 2) Online booking platforms allow patients to directly book appointments at a clinic. They can be open to the public or available solely to patients registered within a specific clinic. 3) Clinical directories propose a searchable list of clinics and medical services available to the public and can show estimated wait times or occupation rates. Some offer a link to a booking platform allowing known patients to directly book an appointment.

\subsection{Clinical reliability of symptom checkers}

Although presented as being as reliable and effective as doctors, the literature reports that symptom checkers still seem to be far from the public's expectations on many fronts [8]. A review on the usage of those apps concluded a lack of solid evidence of the safety and effectiveness in a clinical setting as well as in the triaging of patients, where the top symptom checkers reached an accuracy of $51 \%$, compared to $84 \%$ by physicians $[8,9]$. Respondents 3 and 4 mentioned that triage in a clinical setting needs access to the vital signs of the patients, collected at the evaluation. To be more accurate, a digital tool would need this information, which would then demand the use of external devices by the patient. Another downside of symptom checkers is to prevent undue complication which could lead to bad press and legal actions, they can choose to send patients to the ER preventively. This aversion to risk can in turn lead to higher care and ER usage [10]. 


\subsection{Ethics and privacy issues}

In a public health system, access to care should be free of cost for everyone and efforts should be made to lower barriers of access if they are inevitable. The usage of IT by patients poses the question of equality of access to technology and to the service. Even if the use of computers and mobile devices is on the rise in Quebec, with 85\% owning a computer, and $79 \%$ a mobile phone, there is still around $15 \%$ of the population that don't have access to them in their home [11]. Respondent 4 highlighted the "tech divide", mentioning that educated and "high-tech" patients are those that can find the online tools and the information they need. They are also more likely to have a family physician, and less likely to come to the ER. We must be wary that the usage of digital tools to promote timely and proper access to care can amplify the already existing inequalities of care.

Privacy concerns about the patient's data is also of importance. The storage and handling of patient's data warrants that the highest security measures and safeguards are in place. Unlike the United States and the UK who published guidelines for the development and approval of digital tools, Canada is still lacking in that area [12]. The adoption and publication of strong regulation by the government could help foster the trust of the public in the use of digital tools for health.

\subsection{Technological challenges}

The lack of integration between the digital tools and the systems used in clinics is one of the key technological challenges. It hinders the continuity of care, requires more manual labor and data reentry which is error prone [13]. Respondent 3 mentioned that care workers don't want yet another tool to use in their already cluttered technological environment. Digital tools need to be integrated in existing tools and workflows, which demands investments, development and the approval of the company developing it. The challenge is then to be able to have tools that add much value to the patient and healthcare provider, while demanding minimal effort on the provider side.

\subsection{Organizational barriers}

In Quebec, medical clinics are private entities where physicians work offering medical service to the patients, free of charge, but seeking a profit. As such, they are concerned with the cost and efficacy of their clinics, meaning that the use of digital tools should not cause financial losses. Respondent 2 mentioned that maintaining bookings on the RVSQ portal had a financial impact on the clinic as it took time to manage the bookings, validate reservations and manually reopen appointments if a patient had cancelled it using the RVSQ. He also mentioned that solutions could have been found earlier if they had been consulted. Clinics also need to offer timely appointments to their registered patients. Respondent 3 mentioned that this imposes a balance between offering walk-ins for everyone and maintaining places for current patients. Tools that help clinics do this could encourage the uptake of online booking and offer better access to care and reduce the overuse of ER for patients without a family physician.

One of the respondents mentioned an unforeseen impact that online booking could have, by letting anyone come in his clinics, located in a vulnerable area where many patients' native language was neither English nor French. Respondent 2 mentioned that receiving patients from diverse socioeconomic backgrounds could pose a security risk for his clinic, demanding security investment and proper access to interprets. 
Table 1. List of available digital tools and services

\begin{tabular}{|c|c|c|c|}
\hline Name & Type & Clients & Digital tools \\
\hline ADA Your health guide & AI based symptom checker & Patients & Mobile application \\
\hline Babylon Health & AI based symptom checker & Patients & Mobile application \\
\hline DXA & AI based symptom checker & Patients & Mobile application \\
\hline Tap Medical & $\begin{array}{l}\text { Clinic directory } \\
\text { Online booking }\end{array}$ & $\begin{array}{l}\text { Clinics } \\
\text { Patients }\end{array}$ & $\begin{array}{l}\text { Web } \\
\text { Mobile application }\end{array}$ \\
\hline NAVA MedQ & $\begin{array}{l}\text { Clinic directory } \\
\text { Online booking }\end{array}$ & $\begin{array}{l}\text { Clinics } \\
\text { Registered patients }\end{array}$ & $\begin{array}{l}\text { Web } \\
\text { Mobile application }\end{array}$ \\
\hline GO Rendez-Vous & Clinic directory & Health professionals & Web site \\
\hline Petal MD & Online booking & $\begin{array}{l}\text { Clinics } \\
\text { Patients }\end{array}$ & $\begin{array}{l}\text { Web } \\
\text { Mobile application }\end{array}$ \\
\hline $\begin{array}{l}\text { Chronometriq } \\
\text { (Pomelo Health) }\end{array}$ & Online booking & $\begin{array}{l}\text { Clinics } \\
\text { Patients }\end{array}$ & $\begin{array}{l}\text { Web } \\
\text { Mobile application }\end{array}$ \\
\hline Bonjour Santé & Online booking & Patients & Web site \\
\hline $\begin{array}{l}\text { Rendez-vous Santé } \\
\text { Québec }\end{array}$ & Online booking & Patients & Web site \\
\hline Indexsanté.ca & Clinic directory & Health professionals & Web site \\
\hline Clinia & Clinic directory & Health professionals & Web site \\
\hline
\end{tabular}

\section{Discussion and conclusion}

There is an undisputed need to provide a better access to primary care for patients and that the lack of access leads to an overuse of ER and lower performance for healthcare systems. If digital tools cannot replace a nurse which can assess both the physical and emotional response of the patient, they could offer patients a better sense of the gravity of the symptoms they experience and guide them to the proper service. Each digital tool that was analyzed in this survey tried to mobilize IT to solve the problem of patient accessibility to primary care. As one of the interviewees said: "Every morning at 8am, there are people on the phone that look for a way not to come at the ER" [Respondent 4]. While digital tools try to address a part of this problem, we argue that the lack of single apps integrating the different needed features might cause more confusion, as also observed in other countries [14]. Also, misalignment of incentives and processes lead to the resistance of public efforts by the government of Quebec to offer online booking. In 2019 , only $6,5 \%$ of physicians were offering appointments through the platform and $25 \%$ of those appointments were not even used by patients [15].

This research has certain limits. First it targets the tools and the opinion of the professionals without considering the patients' view on the barriers to primary care and how digital tools could mitigate them, or the barriers to their usage. This important matter should be addressed in future research as a necessary input for decision makers. Second, this study took place before the COVID-19 pandemic and the rapid uptake of digital tools that followed, which spurred interest in virtual care and digital tools. Finally, the quality of digital tools hasn't been assessed either on their safe use or concerning the protection of the patients' data. This remains an area where there is a lack of regulation that needs to be filled in conjunction with adaptative quality evaluation frameworks [12].

This environmental scan allowed us to see that the technology is available and revealed the many complexities of using it to improve access to care from the professional point of view. Following this project, we suggest that a coordinated leadership effort is needed to overcome the challenges of implementing and using digital 
tools that requires a comprehensive design taking into account the needs and realities of each of the professionals, healthcare organizations and the patients.

\section{References}

[1] Fournier J, Heale R, Rietze LL. I can't wait: advanced access decreases wait times in primary healthcare. Healthc Q. 2012;15(1):64-8.

[2] Gupta D, Denton B. Appointment scheduling in health care: Challenges and opportunities. IIE Transactions. $2008 \mathrm{Jul}$ 15;40(9):800-19.

[3] Accès aux services médicaux de première ligne - Professionnels de la santé - MSSS. Available at: https://www.msss.gouv.qc.ca, Accessed August 12, 2020.

[4] Canadian Association of Emergency Physicians Working Group on the Future of Emergency Medicine in Canada. The future of emergency medicine in Canada: submission from CAEP to the Romanow Commission. Part 2. CJEM. 2002 Nov;4(06):431-8.

[5] Benigeri M, Robitaille A. Utilisation des urgences en santé mentale et en santé physique au Québec. Commissaire à la santé et au bien-être; 2017 p. 1-88.

[6] Rowel R, Moore ND, Nowrojee S, Memiah P, Bronner Y. The Utility of the Environmental Scan for Public Health Practice: Lessons from an Urban Program to Increase Cancer Screening. JNMA. 2005;97(4):8.

[7] CIHI. Sources of Potentially Avoidable Emergency Department Visits. heq. 2014 Dec 25;17(4):82-82.

[8] Millenson ML, Baldwin JL, Zipperer L, Singh H. Beyond Dr. Google: the evidence on consumer-facing digital tools for diagnosis. Diagnosis. 2018 Sept 25;5(3):95-105.

[9] Semigran HL, Levine DM, Nundy S, Mehrotra A. Comparison of Physician and Computer Diagnostic Accuracy. JAMA Intern Med. 2016 Dec 1;176(12):1860.

[10] Semigran HL, Linder JA, Gidengil C, Mehrotra A. Evaluation of symptom checkers for self-diagnosis and triage: audit study. BMJ. 2015 July 8;h3480.

[11] CEFRIO. Portrait numérique des foyers québécois. Available at: https://cefrio.qc.ca, Accessed February $19,2020$.

[12] Jogova M, Shaw J, Jamieson T. The Regulatory Challenge of Mobile Health: Lessons for Canada. Healthc Policy. Feb 2019;14(3):19-28.

[13] Godinho MA, Jonnagaddala J, Gudi N, Islam R, Narasimhan P, Liaw S-T. mHealth for Integrated PeopleCentred Health Services in the Western Pacific: A Systematic Review. IJMI. 2020 Oct;142:104259.

[14] Alanzi T. A Review of Mobile Applications Available in the App and Google Play Stores Used During the COVID-19 Outbreak. J Multidiscip Healthc. 2021;14:45-57.

[15] Ministère de la Santé et des Services sociaux. Mesure de l'accès aux soins de santé et aux services sociaux : indicateurs. Available from: https://www.vgq.qc.ca/, Accessed January 11, 2020. 